\title{
q-GENERALIZED BERNSTEIN-DURRMEYER POLYNOMIALS
}

\author{
P. N. Agrawal, A. M. ACU And R. RuChi
}

\begin{abstract}
The purpose of the present paper is to introduce a $q$-Durrmeyer variant of generalizedBernstein operators proposed by Chen et al. (2017). The convergence rate of these operators is examined by means of the Lipschitz class and the Peetre's K-functional. Also, we define the bivariate case of these operators and study the degree of approximation with the aid of the partial moduli of continuity and higher order modulus of continuity via Peetre's K-functional approach. Finally, we introduce the GBS (Generalized Boolean Sum) of the considered operators and investigate the approximation of the Bögel continuous and Bögel differentiable functions with the aid of the Lipschitz class and the mixed modulus of smoothness. Some numerical examples with illustrative graphics have been added to validate the theoretical results and also compare the rate of convergence by using Matlab algorithms.
\end{abstract}

Mathematics subject classification (2010): 41A10, 41A25, 41A36, 41A60.

Keywords and phrases: Bögel continuous, Bögel differentiable, generalized Boolean sum, Peetre's K-functional, Lipschitz class, mixed modulus of smoothness.

\section{REFERENCES}

[1] A. M. ACU, V. Gupta, N. Malik, Local and Global Approximation for Certain ( $p, q)$-Durrmeyer Type Operators, Complex Analysis and Operator Theory, 2017, https://doi.org/10.1007/s11785-017-0714-0.

[2] A. M. Acu, C. V. Muraru, D. F. Sofonea, V. A. Radu, Some approximation properties of a Durrmeyer variant of q-Bernstein-Schurer operators, Mathematical Methods in Applied Science, 39(18) (2016), 5636-5650.

[3] A. M. ACU, I. RAŞA, New estimates for the differences of positive linear operators, Numerical Algorithms, 73(3) (2016), 775-789.

[4] P. N. Agrawal AND N.ISPIR, Degree of Approximation for Bivariate Chlodowskee Szász Charlier Type Operators, Results. Math. 69 (3) (2016), 369-385.

[5] C. BadeA, I. BAdeA AND H. H. GonsKa, A test function theorem and approximation by pseudopolynomials, Bull. Austral. Math. Soc. 34 (1986), 95-108.

[6] C. BADEA, I. BADEA AND H. H. GonsKA, Notes on the degree of approximation of B-continuous and B-differentiable functions, J. Approx. Theory Appl. 4 (1988), 95-108.

[7] K. BÖGEL, Mehrdimensionale Differentiation von Funtionen mehrerer Veränderlicher, J. Reine Angew. Math. 170 (1934), 197-217.

[8] K. BöGEL, Über die mehrdimensionale Differentiation, Integration und beschränkte Variation, J. Reine Angew.Math. 173 (1935), 5-29.

[9] P. L. BUtZER AND H. BERENS, Semi-groups of operators and approximation, Springer New York, Xit 318 pp. (1967).

[10] X. Chen, J. TAN, Z. LiU AND J. Xie, Approximation of functions by a new family of generalized Bernstein operators, J. Math. Anal. Appll. 450(2017), 244-261.

[11] Z. DitZIan And V. Totik, Moduli of Smoothness, Springer, New York (1987).

[12] E. Dobrescu AND I. MATEI, The approximation by Bernstein type polynomials of bidimensionally continuous functions (Romannian), An. Univ. Timişoara Ser. Sti. Mat.-Fiz. 4 (1966), 85-90.

[13] J. L. DURRMEYER, Une formule d'inversion de la transformée de Laplace: Applications à la théorie des moments, Thèse de 3e cycle, Faculté des Sciences de l'Université de Paris, 1967. 
[14] H. Gonska, X. L. Zhou, A Global Inverse Theorem on Simultaneous Approximation by BernsteinDurrmeyer Operators, J. of Approx. Th., 67 (1991), 284-302.

[15] V. Gupta, A. M. ACU, D. F. SofoneA, Approximation Baskakov type Polya-Durrmeyer operators, Applied Mathematics and Computations, 294(1), 2017, 318-331.

[16] V. GuptA, Some approximation properties of q-Durrmeyer operators, Appl. Math. and Comput. 197(2008), 172-178.

[17] A. KaJla And DAn MiclăUş, Blending Type Approximation by GBS Operators of Generalized Bernstein-Durrmeyer Type, Results Math. 73 (1), (2018), 1422-6383.

[18] C. V. Muraru, A. M. ACu, Some Approximation Properties of q-Durrmeyer-Schurer Operators, Scientific Studies and Research Series Mathematics and Informatics, 23(1) (2013), 77-84.

[19] T. Neer, A. M. ACU, P. N. AgRawal, Bezier variant of genuine-Durrmeyer type operators based on Polya distribution, Carpathian Journal of Mathematics, 33(1), 2017, 73-86.

[20] T. NEER, A. M. ACU, P. N. AgRAWAL, Approximation of functions by bivariate q-Stancu-Durrmeyer type operators, Mathematical Communications, 23(2018), 161-180.

[21] O. T. Pop, Approximation of B-continuous and B-differentiable functions by GBS operators defined by infinite sum, J. Inequal. Pure Appl. Math. 10 (2009), no. 1, Article 7, 8 pp.

[22] R. RUChI, B. BAXHAKU AND P. N. AgRAwAL, GBS operators of bivariate Bernstein-Durrmeyertype on a triangle, 41 (7) (2018), 2673-2683.

[23] M. Sidharth, N. IspiR AND P. N. AgRawal, GBS operators of Bernstein Schurer Kantorovich type Based on q-integers, Appl. Math. Comput., 269 (2015), 558-568. 